\title{
Epidemiological Evaluation of the Association between Parental Factor and Newborns Anthropometric Indices
}

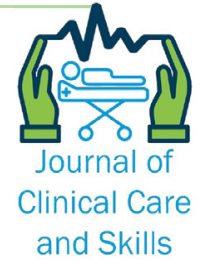

\section{ARTICLE INFO}

\section{Article Type}

Original Research

\section{Authors}

Mousavizadeh A. ${ }^{1} M D, P h D$,

Pourmahmoudi A. ${ }^{* 2} P h D$,

Hosseinikia $\mathrm{M}^{2}{ }^{2} \mathrm{MSc}$

Tabeshfar Z. ${ }^{2} M S C$

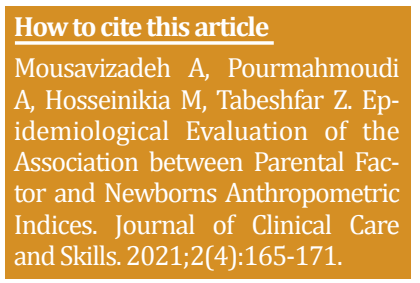

${ }^{1}$ Social Determinant of Health Research Center, Yasuj University of Medical Sciences Yasuj, Iran

2 Department of Nutrition, School of Health, Yasuj University of Medical Sciences, Yasuj, Iran

\section{*Correspondence}

Address: Imam Hossein Square, Shahid Dastjerdi St., next to Shahid Damideh Boyerahmad Health Center.

Postal Code: 7591875114

Phone: +98 (74) 33225519

Fax: +98 (74) 33226715

pourmahmoudi@gmil.com

\section{Article History}

Received: December 1, 2021

Accepted: December 29, 2021

ePublished: January 19, 2022

\section{A B S T R A C T}

Aims Identification and management of factors affecting fetal development can be a valuable contribution to promoting infant survival, growth, and development. This study investigated the association between parental factors and newborns' anthropometric indices.

Materials \& Methods This cross-sectional study was based on secondary data analysis of pediatric and pregnancy surveillance systems in which 1500 children below the age of 2 years were selected by proportional sampling method. The outcome indexes in this study included birth weight, height, and head circumference. Data analysis conducted by SPSS 16 using the generalized linear model approach with logit link function and binomial probability distribution were used in this study.

Findings The prevalence of low-birth-weight, short stature, and small birth head circumference were estimated to be $3.3 \%, 4.2 \%$, and $4.4 \%$, respectively. In the generalized linear model with logit link function, predictor variables of birth weight included occupation, a paternal education level $(\mathrm{p}<0.05)$, education level, BMI, and pregnancy rates of the mother $(\mathrm{p}<0.05)$. The predictor variables of birth height were paternal occupation, baby gender, and maternal body mass index $(\mathrm{p}<0.05)$.

Conclusion The need to pay attention to parent-related intervening factors such as BMI and birth rank in the family empowerment programs to improve birth indicators is suggested.

Keywords Birth Weight; Anthropometry; Infants; Pregnancy

\section{I T A T I O N L I N K S}

[1] Does reducing infant mortality depend on preventing low ... [2] UN Inter-agency Group for Child Mortality Estimation. National, regional, and global ... [3] Prevalence of low birth weight and its association ... [4] Prevalence and risk factors ... [5] The epidemiology of low ... [6] Maternal race/ethnicity and predictors of pregnancy ... [7] The World Health Organization global database ... [8] Head circumference - a useful single parameter for skull ... [9] Etiology and genetic diagnosis of short stature ... [10] Birth outcomes of ... [11] Nutritional ... [12] How consistent are associations between ... [13] Maternal education level and low birth weight ... [14] The effect of maternal anemia on the anthropometric ... [15] Relationship between maternal hematologic ... [16] Social factors and pregnancy weight gain in relation to infant birth ... [17] Survey on anthropometric parameters of neonates at birth and ... [18] Biomechanics of pediatric manual wheelchair ... [19] Effects of multiple ventilation courses and duration of mechanical ... [20] Trends and challenges in international pediatric ... [21] The relationship between maternal HCT levels, birth ... [22] Low birth weight in Iran: Implications from a systematic ... [23] Birthweight and risk factors for cardiovascular diseases ... [24] Maternal underweight and the risk of preterm birth and low birth ... [25] Maternal morbid obesity and the risk of adverse pregnancy ... [26] Maternal anemia during pregnancy ... [27] Relationship between maternal hemoglobin ... [28] Hemoglobin, altitude and birth weight ... [29] Prevalence of short stature, underweight, overweight ... [30] Characteristics and Gender Differences in Prepubertal ... [31] Current status and the 10 years trend in the malnutrition ... [32] Prevalence of malnutrition in Saudi children ... [33] Risk factors for stunting among ... [34] Effect of mother's education on child's nutritional ... [35] Reference curves of birthweight, length, and head ... [36] Racial, ethnic, and economic disparities ... [37] Encyclopedia of ... 


\section{Introduction}

The neonatal mortality rate (NMR) is one of each country's most important health indicators. There is a logical relationship between maternal health, the quantity and quality of prenatal care, socioeconomic and cultural factors of the family with infant mortality [1, 2]. Neonatal birth indexes such as low birth weight (LBW) and weight $<2500 \mathrm{gr}$ at birth are the leading causes of undesirable health outcomes, especially infant mortality in developing countries. About $15.5 \%$ of all births are LBW, and $95.6 \%$ occur in developing countries. In a study conducted by Momeni et al., the prevalence of LBW was 9.4\% in the southeast of Iran ${ }^{[3,4]}$. The prevalence of this problem in industrialized countries is $7 \%$, with most cases related to the non-white race $[5,6]$.

In addition to weight, birth height and head circumference are valid indexes for fetal development. According to the World Health Organization, in 2003, about 164 million children under five years were suffering from short stature [7, 8]. According to the UNICEF report in 2013, the global outbreak of this index has declined; however, one of every four children under the age of five years is still short stature $(26 \%$ in 2011). These statistics are more prevalent in rural areas, and poor societies are twice as high as rich societies ${ }^{[4,9]}$. Anthropometry is one of the key epidemiological tools for estimating nutritional status and health. Therefore, these three indexes are the most important and most common criteria for assessing infants' mental and physical health and indirectly predicting the life expectancy at birth in each country ${ }^{[10,11]}$.

Maternal anemia, paternal education, and job are the main factors affecting children's anthropometric status. On the other hand, educated parents enjoy superior knowledge in relation to child development and health and provide their children with more educational facilities [12]. But, Silvestrin et al. found no significant relationship between low birth weight and maternal education [13]. AL-Hajjiah et al. concluded that maternal anemia could adversely affect neonate's anthropometric status [14]. Also, in a study, a significant positive relationship between birth weight and maternal indices, including hemoglobin and hematocrit, BMI, and maternal weight in pregnancy was observed [15]. Still, in Maddah et al., no significant relationship was observed between birth weight and maternal weight ${ }^{[16] .}$

Many of the factors affecting fetal development and indexes of birth weight, height, and chest and head circumference have been identified so far, but the studies have shown contradictory results. On the other hand, the importance and priority of factors and their severity and weakness vary from one country to another under different social, biological, and economic conditions. Therefore, the present study investigated the association between parental factors and newborns' anthropometric indices.

\section{Materials and Methods}

This cross-sectional study was conducted from 2017 to 2018 based on secondary data analysis of pediatric and pregnancy surveillance systems in which 1500 children under the age of 2 years were covered by the Health Care Centers of Kohgiluyeh and Boyer-Ahmad province were randomly selected. Herein, 134 cases were excluded from the study due to incomplete data. A total of 1336 good-quality records were examined to determine the relationship between the indexes before and during pregnancy with birth anthropometric variables. The cases were initially chosen by proportional random sampling method from the records of children two years old. The inclusion criterion for the records was 95\% completion of the data necessary for the study. We excluded any records with defective information.

Occupation, parental education, maternal anemia in the first and second trimester of pregnancy, pregnancy rates, maternal BMI at the onset of pregnancy, and baby gender were the most important variables selected from the records. Anemia was defined according to the World Health Organization. The data collection tool was a checklist in which these variables were recorded.

The standard anthropometric indices were calculated based on the formulas provided by the World Health Organization according to the Z score and the final classification based on three indicators of weight for age, weight for height, and height for age, respectively describing Low weight, stunting, and short height. The $\mathrm{Z}$ score normal ranges based on different levels of severity are as follow:

Green: $\geq-1$ and $\leq+1$ SD;

Gold: $\geq-2$ and $<-1$ SD; or $>+1$ and $\leq+2$ SD;

Red: $\geq-3$ and $<-2$ SD; or $>+2$ and $\leq+3$ SD,

Black: $<-3$ or $>+3$ SD [15].

The independent indices in this study were birth weight, height, and head circumference, measured and recorded by experienced and trained personnel through the current surveillance system after referring pregnant mothers to rural or urban health care centers. Birth weight had been measured in gr with an accuracy of \pm 100 gr. Birth height and head circumference had been measured with standard instruments in surveillance systems and with an accuracy of $\pm 0.5 \mathrm{~cm}$ ).

Concerning the four continuous quantitative variables and the binary dependent variables, the generalized linear model (GLM) approach with logit link function and binomial probability distribution were used in this study. The significant level was considered $\leq 0.05$ for two-tailed hypothesis tests, and confidence interval estimates for model parameters were 95\%. The odds ratio was considered an indicator of the model's predictive power. Data analysis was conducted by SPSS 16. 


\section{Findings}

We considered 1366 infants (47.6\% girls and 52.4\% boys). The prevalence of LBW, short stature, and small birth head circumference was estimated to be $3.3 \%, 4.2 \%$, and $4.4 \%$, respectively, all three of which were more common in girls. This difference (boygirl) was more evident in the head circumference index $(5 \%, 3 \%$, respectively). The mean weight, height, and head circumference at birth in the boys were higher than in the girls. This difference was statistically significant $(p=0.012)$. The median weight of the boys was $100 \mathrm{gr}$ higher than girls. Concerning the birth height and head circumference, the median height and head circumference indices were the same in both groups (Table 1 ).

The 5th and 10th percentiles showed the same weight in both genders, but the corresponding values in the boys were larger than in the girls in the 25th and 50th percentiles of the weight. The values were again the same in the 75th and 90th percentiles in both groups, but the corresponding values in the boys were larger than in the girls in the 95th percentile. In the case of infant height, the status was the same in both genders from 5th to 75th percentiles, and the corresponding values in the boys were larger than in the girls only in the 90th and 95th percentiles (Table 2).

The percentage of low birth weight was 3.3\% in total,
Mousavizadeh A. et al.

and $3.1 \%$ and $3.5 \%$ respectively in the boys and the girls. The percentage of short stature was $4.2 \%$ in total, and 3.1 and 5.3 respectively in the boys and girls. At birth, the low head circumference was $4.4 \%$ in total, and 3\% and 5\% respectively in the boys and girls (Table 3).

Continuous Variable Information used as a covariate in the generalized linear model (logit function) shows that the age range was 14-51 years in mothers and 21-74 years in fathers of the infants. The mean age of fathers was 5 (1.2-5.8) years older than mothers. At the onset of pregnancy, the mean maternal body mass index was 25.57 (24.6-26.2), indicating a slight overweight in women. The mean number of maternal pregnancies was $2.25 \pm 0.86$ (Table 4 ).

The predictor factors of the weight were paternal occupation, maternal and paternal education level, maternal body mass index, and the pregnancy number. The predictor factors of the birth height were the child's gender, paternal occupation, and maternal body mass index.

The predictor factors of the head circumference included baby gender, maternal anemia during the first trimester of pregnancy, and maternal education (Table 5).

Among the mentioned variables, paternal occupation was a predictor for all three anthropometric indices of the infants.

Table 1) neonate anthropometry index distribution at the birth time by gender

\begin{tabular}{|c|c|c|c|c|c|c|c|}
\hline \multirow[t]{2}{*}{ Variables } & \multirow[t]{2}{*}{ Gender } & \multirow[t]{2}{*}{ Mean \pm SD } & \multicolumn{2}{|c|}{ 95\% Confidence Interval for Mean } & \multirow[t]{2}{*}{ IQR } & \multirow[t]{2}{*}{ t. } & \multirow[t]{2}{*}{ p. } \\
\hline & & & Lower & Upper & & & \\
\hline \multirow[t]{2}{*}{ Weight (gr) } & Girl & $3058.32 \pm 477.70$ & 3021.12 & 3095.52 & 700 & -2.491 & 0.013 \\
\hline & Boy & $3125.00 \pm 498.30$ & 3088.02 & 3161.98 & 600 & & \\
\hline \multirow[t]{2}{*}{ Height $(\mathrm{cm})$} & Girl & $49.47 \pm 2.41$ & 49.28 & 49.65 & 3 & -2.815 & 0.005 \\
\hline & Boy & $49.83 \pm 2.30$ & 49.66 & 50.01 & 3 & & \\
\hline \multirow[t]{2}{*}{ Head Circumference $(\mathrm{cm})$} & Girl & $34.54 \pm 1.39$ & 34.44 & 34.65 & 1.50 & -4.865 & 0.000 \\
\hline & Boy & $34.91 \pm 1.38$ & 34.80 & 35.03 & 2.00 & & \\
\hline
\end{tabular}

Table 2) Percentile distribution of anthropometric index at birth time

\begin{tabular}{|c|c|c|c|c|c|c|c|c|}
\hline \multirow[t]{2}{*}{ Variables } & \multirow[t]{2}{*}{ Gender } & \multicolumn{7}{|c|}{ Percentiles } \\
\hline & & 5 & 10 & 25 & 50 & 75 & 90 & 95 \\
\hline \multirow{2}{*}{$\overline{\text { Weight (gr) }}$} & Girl & 2400.00 & 2500.00 & 2700.00 & 3000.00 & 3400.00 & 3700.00 & 3900.00 \\
\hline & Boy & 2400.00 & 2500.00 & 2800.00 & 3100.00 & 3400.00 & 3700.00 & 4000.00 \\
\hline \multirow{2}{*}{ Height $(\mathrm{cm})$} & Girl & 45.00 & 47.00 & 48.00 & 50.00 & 51.00 & 52.00 & 53.00 \\
\hline & Boy & 46.00 & 47.00 & 48.00 & 50.00 & 51.00 & 53.00 & 54.00 \\
\hline \multirow[t]{2}{*}{ Head Circumference $(\mathrm{cm})$} & Girl & 32.00 & 33.00 & 34.00 & 35.00 & 35.50 & 36.00 & 37.00 \\
\hline & Boy & 33.00 & 33.00 & 34.00 & 35.00 & 36.00 & 36.50 & 37.00 \\
\hline
\end{tabular}

Table 3) Results of frequency of dependent variable information by the gender of the neonate (Numbers in parentheses are in percent)

\begin{tabular}{|c|c|c|c|c|}
\hline \multirow[t]{2}{*}{ Variables } & & \multicolumn{2}{|l|}{ Gender } & \multirow[t]{2}{*}{ Total } \\
\hline & & Boy & Girl & \\
\hline \multirow[t]{2}{*}{ Weight (gr) } & Low & $22(3.10)$ & $22(3.50)$ & $44(3.3)$ \\
\hline & Normal & $678(96.9)$ & $614(95.5)$ & \\
\hline \multirow[t]{2}{*}{ Height $(\mathrm{cm})$} & Low & $22(3.10)$ & $34(5.30)$ & $56(4.2)$ \\
\hline & Normal & $678(96.9)$ & $602(94.7)$ & \\
\hline \multirow[t]{2}{*}{ Head Circumference $(\mathrm{cm})$} & Low & $21(3.0)$ & $38(5.0)$ & $59(4.4)$ \\
\hline & Normal & $679(97)$ & $598(94)$ & \\
\hline
\end{tabular}


Table 4) Categorical Variable Information used as predictors and dependent variable in the verbalized linear model

\begin{tabular}{|c|c|c|}
\hline Factor & Number & Percent \\
\hline \multicolumn{3}{|l|}{ Gender } \\
\hline Girl $=0$ & 636 & 47.6 \\
\hline Boy $=1$ & 700 & 52.4 \\
\hline \multicolumn{3}{|c|}{ Anemia at first trimester } \\
\hline Yes $=0$ & 356 & 26.6 \\
\hline $\mathrm{No}=1$ & 980 & 73.4 \\
\hline \multicolumn{3}{|c|}{ Anemia at second trimester } \\
\hline Yes $=0$ & 403 & 30.2 \\
\hline No $=1$ & 933 & 69.8 \\
\hline \multicolumn{3}{|c|}{ Education of mother } \\
\hline Illiterate $=0$ & 779 & 58.3 \\
\hline Literate $=1$ & 557 & 41.7 \\
\hline \multicolumn{3}{|l|}{ Job of father } \\
\hline Employee $=0$ & 274 & 20.5 \\
\hline Free $=1$ & 622 & 46.6 \\
\hline Worker $=2$ & 399 & 29.9 \\
\hline Shopper $=3$ & 41 & 3.1 \\
\hline \multicolumn{3}{|c|}{ Education of father } \\
\hline Illiterate $=0$ & 630 & 47.2 \\
\hline literate $=1$ & 706 & 52.8 \\
\hline
\end{tabular}

Table 5) Parameter estimates for predictors variables in a generalized linear model with a logit function

\begin{tabular}{|c|c|c|c|c|c|c|c|c|c|c|c|c|}
\hline \multirow[t]{3}{*}{ Independent variable } & \multicolumn{4}{|l|}{ Weight } & \multicolumn{4}{|c|}{ Length } & \multicolumn{4}{|c|}{ Head Circumference } \\
\hline & \multirow[t]{2}{*}{ p-value } & \multirow[t]{2}{*}{ OR } & \multicolumn{2}{|c|}{$\begin{array}{l}95 \% \text { Wald } \\
\text { CI for OR }\end{array}$} & \multirow[t]{2}{*}{$\begin{array}{l}\mathrm{p}- \\
\text { value }\end{array}$} & \multirow[t]{2}{*}{ OR } & \multicolumn{2}{|c|}{$\begin{array}{l}95 \% \text { Wald } \\
\text { CI for OR }\end{array}$} & \multirow[t]{2}{*}{$\begin{array}{l}\mathrm{p}- \\
\text { value }\end{array}$} & \multirow[t]{2}{*}{ OR } & \multicolumn{2}{|c|}{$\begin{array}{l}95 \% \text { Wald } \\
\text { CI for OR }\end{array}$} \\
\hline & & & Lower & Upper & & & Lower & Upper & & & Lower & Upper \\
\hline Neonate gender=Boy/Girl & 0.61 & 1.09 & 0.78 & 1.55 & 0.001 & 1.802 & 1.276 & 2.546 & 0.00 & 2.052 & 1.449 & 2.906 \\
\hline $\begin{array}{l}\text { anemia in first } \\
\text { trimester }=\text { no } / \text { yes }\end{array}$ & 0.14 & 1.35 & 0.91 & 2.03 & 0.725 & 0.927 & 0.609 & 1.412 & 0.04 & 1.501 & 1.013 & 2.223 \\
\hline $\begin{array}{l}\text { anemia in second } \\
\text { trimester }=\text { no } / \text { yes }\end{array}$ & 0.61 & 0.92 & 0.60 & 1.33 & 0.271 & 1.246 & 0.842 & 1.843 & 0.11 & 1.371 & 0.937 & 2.008 \\
\hline Job of father $=2 / 1$ & 0.00 & 4.05 & 1.82 & 9.02 & 0.018 & 0.343 & 0.142 & 0.831 & 0.00 & 0.231 & 0.100 & 0.536 \\
\hline Job of father $=3 / 1$ & 0.04 & 1.92 & 1.01 & 3.66 & 0.108 & 0.525 & 0.239 & 1.153 & 0.01 & 0.397 & 0.194 & 0.813 \\
\hline Job of father $=2 / 3$ & 0.01 & 2.55 & 1.27 & 5.14 & 0.035 & 0.413 & 0.182 & 0.938 & 0.06 & 0.497 & 0.238 & 1.039 \\
\hline $\begin{array}{l}\text { Education level of } \\
\text { mother=illiterate/literate }\end{array}$ & 0.00 & 3.04 & 2.02 & 4.58 & 0.314 & 0.808 & .533 & 1.224 & 0.07 & 0.681 & 0.451 & 1.029 \\
\hline $\begin{array}{l}\text { Education level of } \\
\text { father=illiterate/literate }\end{array}$ & 0.00 & 3.53 & 2.31 & 5.38 & 0.063 & 1.485 & 0.979 & 2.253 & 0.07 & 1.451 & 0.964 & 2.183 \\
\hline Age of mother & 0.50 & 0.99 & 0.95 & 1.03 & 0.667 & 1.009 & 0.969 & 1.051 & 0.98 & 1.000 & 0.961 & 1.042 \\
\hline Age of father & 0.65 & 0.99 & 0.96 & 1.03 & 0.247 & 1.020 & 0.987 & 1.054 & 0.46 & 1.013 & 0.979 & 1.048 \\
\hline BMI of mother & 0.00 & 0.94 & 0.91 & 0.98 & 0.000 & 0.922 & 0.882 & 0.963 & 0.11 & 0.967 & 0.929 & 1.008 \\
\hline Number of pregnancy & 0.01 & 1.26 & 1.05 & 1.51 & 0.942 & 1.006 & 0.864 & 1.171 & 0.47 & 0.943 & 0.803 & 1.106 \\
\hline (Intercept) & 0.00 & 101.11 & 24.01 & 425.81 & 0.00 & 0.17 & 0.036 & 0.840 & 0.00 & 0.102 & 0.023 & 0.459 \\
\hline
\end{tabular}

\section{Discussion}

This study evaluated some of the most important paternal factors affecting children's anthropometric indexes for the first time in Kohgiluyeh and BoyerAhmad province, where the rate of childhood malnutrition is pretty considerable. The indices of weight, height and head circumference at birth are not only predictors of an infant's growth and development but also represent the socioeconomic status of the community.

Results showed that the mean birth weight was higher in boys. These findings are consistent with the results of some other studies $[17,18]$. In this regard, the World Health Organization reported that girls are at higher risk for LBW $[19,20]$. The prevalence of LBW was $3.3 \%$, almost less than half the incidence of this index in the world $(7.7 \%)^{[21]}$. This rate was $9.4 \%$ and $8 \%$ in the studies conducted by Momeni and Ebadi, respectively $[4,22]$. The present study shows the success of maternal and pediatric health programs and the relative improvement of livelihoods of the province's population and other related variables in the years near the study.

In the present study, the most important predictor variables of birth weight were paternal occupation and education, BMI, and pregnancy rates. The first three variables were a partly indirect estimation of the income level, social class of families, and socioeconomic status. This finding is inconsistent with the results of some other studies [16,23]. Silvestrin et al. found no significant relationship between low birth weight and maternal education, probably due to the poor socioeconomic status of mothers [13].

Another predictor variable for birth weight was maternal BMI. In women with low BMI, the prevalence of LBW was higher compared with those with normal BMI. This finding is in line with the results of many studies. Han et al. on data from 78 studies with the sample size of $1,025,794$ women in two EMBASE and MEDLINE databases from the baseline until January 2009 showed a significant correlation between low maternal weight based on 
BMI and LBW index, which has been statistically significant in both developing and developed countries [24]. Toosi et al. indicated that the mean weight of newborns was increased significantly with maternal weight gain during pregnancy.

In contrast, weight gain, BMI, hemoglobin, and maternal hematocrit significantly correlated with birth weight. However, in the statistical test of linear regression, maternal weight and BMI at the onset of pregnancy were better predictors of birth weight $[15$, 25]. Contrary to this finding, Maddah et al. observed no significant relationship between maternal weight and maternal overweight with the birth weight of infants [16]. This contradiction might be attributed to several factors: pre-pregnancy weight, maternal age, maternal delivery, the interval between pregnancies, pregnancy diseases, and nutritional status.

The pregnancy rate was another predictor variable of the baby's birth weight in this study, reported in some other studies [4]. Most of the studies have concluded that there is a consensus between maternal hemoglobin concentration and the risk of LBW [26]. In the present study, no statistically significant relationship was found between these two variables. Another study has shown that both low and high hemoglobin levels are associated with an increase in LBW and early delivery ${ }^{[27]}$ because high concentrations of hemoglobin increase the blood viscosity, which disrupts oxygen supply to tissues and causes cerebrovascular complications. In a study, high hemoglobin concentrations have been associated with a lower risk of low birth weight [28].

A nutritional cause of short stature is chronic malnutrition, which fails to reach a height appropriate to the age. In this study, the mean birth height in boys was significantly higher than that in girls $(p=0.005)$, consistent with another study's findings ${ }^{[17]}$. We also indicated that the prevalence of short stature was $4.2 \%$ - which was less than the estimate of this index (4.9\%) in Zayed et al.' study [29]. The girls had a worse situation rather than boys. The most important predictor variables of short stature were gender, paternal occupation, and maternal BMI. The results of studies have confirmed the relationship between short stature at birth and gender $[17,30]$.

In the second national survey on the nutritional status and anthropometric indexes of children under the age of 5 years (ANIS2, 2008), Iranian provinces of Sistan-Baluchestan (16.5\%), Khorasan (8.2\%), and Kohgiluyeh and Boyer-Ahmad (8.5\%) were the three provinces with the highest prevalence of short stature [30]. However, World Health Organization has predicted that the short stature rate of this age group will decline from $29.8 \%$ in 2000 to 16.3 in 2020 for developing countries [1]. Researchers reported that the prevalence of short stature in children under five years was $13.7 \%{ }^{[31]}$. In a study conducted by researchers, this rate was $29.7 \%$ in the same age
Mousavizadeh A. et al.

group [32]. In the present study and the study by Abuya et al., a significant statistical relationship was seen between the boy gender and low birth weight [33], which suggests the predictive importance of the birth weight index in the growth trend of the newborns. UNICEF has confirmed these findings during its most recent report in 2013 [34]. The mean birth head circumference of boys was significantly higher than that of girls. These findings are inconsistent with the results of studies [30,35]. In the study of Tusi et al., all the anthropometric measurements of girls were lower than those of the boys [17]. The prevalence of low birth head circumference was $4.4 \%$, which in girls nearly was twice as large as that of the boys (5\% vs. $3 \%$, respectively); this can be partly due to the biological differences between the two genders. In this study, the most important predictors of head birth circumference were paternal occupation, gender, and maternal anemia in the first trimester of pregnancy. However, no significant relationship was found between this outcome and maternal anemia in the second trimester of pregnancy, partly due to increased maternal iron levels under iron supplementation according to the national maternal care program in the second trimester of pregnancy. In the study of Toosi et al., there was a significant relationship between hemoglobin concentration and hematocrit with weight, height, and head circumference indexes at birth [15].

Among the factors mentioned above, paternal occupation in all three indexes (low birth weight, short stature, and low head circumference) was the predictor that indirectly was estimated by the family income and somehow related to maternal body mass, weight gain during pregnancy, anemia, and maternal nutritional status. Its association with anthropometric indices in newborns has been significant [16, 23]. In a study conducted by Whitehead et al., poverty has shown an independent effect on each pregnancy complication, which is called "First Cause" in epidemiology [36,37].

The current research experienced limitations, including defective information and lack of access to all related data. Large sample size and considering the most remarkable paternal factors could also be considered the most superior strength.

Considering the association of family socioeconomic factors, BMI, anemia, and pregnancy number of the mother on the birth anthropometric variables, it is necessary to pay more attention to the improvement of nutritional status and surveillance systems during pregnancy and the elimination of maternal anemia in the first trimester of pregnancy.

\section{Conclusion}

Despite the higher mean weight of boys at birth than girls, parental factors can explain a significant part of the status of anthropometric indices at birth. Based 
Epidemiological Evaluation of the Association ...

on these findings, the most important parental factors affecting the anthropometric indices of infants, including occupation, level of education, maternal BMI, and birth rank, have shown the most linear relationship with birth indicators.

Acknowledgments: We would like to express our appreciation to network health centers, research deputy of the health and nutrition school, and research deputy of Yasuj University of medical sciences.

Ethical Permissions: The study protocol was approved by the Ethics Committee of the Yasuj University of medical sciences (IR.YUMS.REC.1394.78).

Conflicts of Interests: None declared.

Authors' Contributions: Mousavizadeh A (First Author), Introduction Writer/Methodologist/Main Researcher/ Statistical Analyst/Discussion Writer (25\%); Pourmahmoudi A (Second Author), Assistant Researcher (25\%); Hosseinikia M (Third Author), Assistant Researcher (25\%); Tabeshfar Z (Forth Author), Assistant Researcher (25\%)

Funding/Sources: This work was funded by the deputy of research of Yasuj University of medical sciences.

\section{References}

1- Kramer MS, Barros FC, Demissie K, Liu S, Kiely J, Joseph $\mathrm{K}$. Does reducing infant mortality depend on preventing low birthweight? An analysis of temporal trends in the Americas. Paediatr Perinat Epidemiol. 2005;19(6):445-51. 2- Hug L, Alexander M, You D, Alkema L, UN Inter-agency Group for Child Mortality Estimation. National, regional, and global levels and trends in neonatal mortality between 1990 and 2017, with scenario-based projections to 2030: a systematic analysis. Lancet Glob Health. 2019;7(6):e71020.

3- He Z, Bishwajit G, Yaya S, Cheng Z, Zou D, Zhou Y. Prevalence of low birth weight and its association with maternal body weight status in selected countries in Africa: a cross-sectional study. BMJ Open. 2018;8(8):e020410.

4- Momeni M, Danaei M, Jabbari Nejad Kermani A, Bakhshandeh M, Foroodnia Sh, Mahmoudabadi Z, et al. Prevalence and risk factors of low birth weight in the Southeast of Iran. Int J Prev Med. 2017;8:12.

5- Kramer M. The epidemiology of low birthweight. Nestle Nutr Inst Workshop Ser. 2013;74:1-10.

6- Shiao SYPK, Andrews CM, Helmreich RJ. Maternal race/ethnicity and predictors of pregnancy and infant outcomes. Biol Res Nurs. 2005;7(1):55-66.

7- de Onis M, Blössner M. The World Health Organization global database on child growth and malnutrition: methodology and applications. Int J Epidemiol. 2003;32(4):518-26.

8- Martini M, Klausing A, Lüchters G, Heim N, MessingJünger $M$. Head circumference - a useful single parameter for skull volume development in cranial growth analysis? Head Face Med. 2018;14(1):3.

9- Chen WW, Liu HX, Liu J, Yang LL, Liu M, Ma HJ. Etiology and genetic diagnosis of short stature in children. Chin J Contemporary Pediatr. 2019;21(4):381-6. [Chinese]

10- Alexander GR, Wingate MS, Mor J, Boulet S. Birth outcomes of Asian-Indian-Americans. Int J Gynecol Obstet. 2007;97(3):215-20.

11- Nieman DC. Nutritional assessment. New York: McGraw-Hill; 2019.
170

12- Jeong J, Kim R, Subramanian SV. How consistent are associations between maternal and paternal education and child growth and development outcomes across 39 lowincome and middle-income countries?. J Epidemiol Community Health. 2018;72(5):434-41.

13-Silvestrin S, da Silva CH, Naomi Hirakata V, Goldani AAS, Silveira PP, Goldani MZ. Maternal education level and low birth weight: a meta-analysis. Versão em Português. 2013;89(4):339-45.

14- Al-Hajjiah NN, Almkhadree MA. The effect of maternal anemia on the anthropometric measurements in fullterm neonates. Asian J Pharm Clin Res. 2018;11(4):4224.

15- Toosi M, Akbarzadeh M, Zare N. Relationship between maternal hematologic concentration and BMI in primiparous women on some physiological parameters in neonates. Sci J Iranian Blood Transfus Organ. 2013;10(1):77-85. [Persian]

16- Maddah M, Karandish M, Mohammadpour-Ahranjani B, Neyestani T, Vafa R, Rashidi A. Social factors and pregnancy weight gain in relation to infant birth weight: a study in public health centers in Rasht, Iran. Eur J Clin Nutr. 2005;59(10):1208-12.

17- Judipour Z, Ali Malayeri F, Bagheri S, Bazzi A, Judipour M, Judipour M. Survey on anthropometric parameters of neonates at birth and some effective demographic factors in sistan region. J Ilam Univ Med Sci. 2015;23(Suppl 4):10613. [Persian]

18- Slavens BA, Schnorenberg AJ, Aurit CM, Tarima S, Vogel LC, Harris GF. Biomechanics of pediatric manual wheelchair mobility. Front Bioengin Biotechnol. 2015;3:137.

19- Jensen EA, DeMauro SB, Kornhauser M, Aghai ZH, Greenspan JS, Dysart KC. Effects of multiple ventilation courses and duration of mechanical ventilation on respiratory outcomes in extremely low-birth-weight infants. JAMA Pediatr. 2015;169(11):1011-7.

20- Walker DM, Tolentino VR, Teach SJ. Trends and challenges in international pediatric emergency medicine. Curr Opin Pediatr. 2007;19(3):247-52.

21- Ramazanali F, Dastjerdi MV, Beigi A, Moini A. The relationship between maternal HCT levels, birth weight and risk of low birth weight. Iranian J Pediatr. 2006;16(4):447-54. [Persian]

22- Ebadi F, Ghashghaee A, Bragazzi NL, Martini M, Sepehrian R, Ghaemmohamadi MS, et al. Low birth weight in Iran: Implications from a systematic review of the literature and meta-analysis in the period 1999-2017. Med J Islam Repub Iran. 2018;32(1):13.

23- Kaneshi T, Yoshida T, Ohshiro T, Nagasaki H, Asato Y, Ohta T. Birthweight and risk factors for cardiovascular diseases in Japanese schoolchildren. Pediatr Int. 2007;49(2):138-43.

24- Han Z, Mulla S, Beyene J, Liao G, McDonald SD, Knowledge Synthesis Group. Maternal underweight and the risk of preterm birth and low birth weight: a systematic review and meta-analyses. Int J Epidemiol. 2011;40(1):65101.

25- Cedergren MI. Maternal morbid obesity and the risk of adverse pregnancy outcome. Obstet Gynecol. 2004;103(2):219-24.

26- Levy A, Fraser D, Katz M, Mazor M, Sheiner E. Maternal anemia during pregnancy is an independent risk factor for low birthweight and preterm delivery. Eur J Obstet Gynecol Reprod Biol. 2005;122(2):182-6. 


\section{1}

27- Sekhavat L, Davar R, Hosseinidezoki S. Relationship between maternal hemoglobin concentration and neonatal birth weight. Hematology. 2011;16(6):373-6.

28- Nahum GG, Stanislaw H. Hemoglobin, altitude and birth weight: does maternal anemia during pregnancy influence fetal growth?. J Reprod Med. 2004;49(4):297-305.

29- Zayed AA, Beano AM, Haddadin FI, Radwan SS, Allauzy SA, Alkhayyat MM, et al. Prevalence of short stature, underweight, overweight, and obesity among school children in Jordan. BMC Public Health. 2016;16(1):1040.

30- Ranke MB, Lindberg A, Tanaka T, Camacho-Hübner C, Dunger DB, Geffner ME. Baseline Characteristics and Gender Differences in Prepubertal Children Treated with Growth Hormone in Europe, USA, and Japan: 25 Years' KIGS® Experience (1987-2012) and Review. Horm Res Paediatr. 2017;87(1):30-41.

31- Sheikholeslam R, Naghavi M, Abdollahi Z, Zarati M, Vaseghi S, Sadeghi Ghotbabadi F, et al. Current status and the 10 years trend in the malnutrition indexes of children under 5 years in Iran. Iranian J Epidemiol. 2008;4(1):21-8. [Persian]
Mousavizadeh A. et al.

32- El Mouzan MI, Foster PJ, Al Herbish AS, Al Salloum AA, Al Omar AA, Qurachi MM. Prevalence of malnutrition in Saudi children: a community-based study. Ann Saudi Med. 2010;30(5):381-5.

33- El Taguri A, Betilmal I, Mahmud SM, Ahmed AM, Goulet $\mathrm{O}$, Galan $\mathrm{P}$, et al. Risk factors for stunting among under-fives in Libya. Public Health Nutr. 2009;12(8):1141-9.

34- Abuya BA, Ciera J, Kimani-Murage E. Effect of mother's education on child's nutritional status in the slums of Nairobi. BMC Pediatr. 2012;12:80.

35- Rashidi AA, Kiani O, Heidarzadeh M, Imani B, Nematy M, Taghipour A, et al. Reference curves of birthweight, length, and head circumference for gestational age in iranian singleton births. Iranian J Pediatr. 2018;28(5):e66291.

36- Whitehead NS, Callaghan W, Johnson C, Williams L. Racial, ethnic, and economic disparities in the prevalence of pregnancy complications. Matern Child Health J. 2009;13(2):198-205.

37- Boslaugh S. Encyclopedia of epidemiology. New York: SAGE Publications; 2007. 